\title{
Dynamic Modeling and Vibration Analysis for the Vehicles with Rigid Wheels Based on Wheel-Terrain Interaction Mechanics
}

\author{
Jianfeng Wang, ${ }^{1,2}$ Yiqun Liu, ${ }^{1}$ Liang Ding, ${ }^{1}$ Bing Yan, ${ }^{3}$ Haibo Gao, ${ }^{1}$ Baoyu Song, ${ }^{1}$ Tie Gao, ${ }^{2}$ \\ Yuzhou Hao, ${ }^{1}$ and Mingdi Sun ${ }^{2}$ \\ ${ }^{1}$ State Key Laboratory of Robotics and System, Harbin Institute of Technology, Harbin 150001, China \\ ${ }^{2}$ School of Automotive Engineering, Harbin Institute of Technology, Weihai, Shandong 264209, China \\ ${ }^{3}$ Beijing Institute of Astronautical Systems Engineering, Beijing 100076, China \\ Correspondence should be addressed to Liang Ding; liangding@hit.edu.cn
}

Received 31 August 2014; Revised 16 February 2015; Accepted 16 February 2015

Academic Editor: Sakdirat Kaewunruen

Copyright (C) 2015 Jianfeng Wang et al. This is an open access article distributed under the Creative Commons Attribution License, which permits unrestricted use, distribution, and reproduction in any medium, provided the original work is properly cited.

\begin{abstract}
The contact mechanics for a rigid wheel and deformable terrain are complicated owing to the rigid flexible coupling characteristics. Bekker's equations are used as the basis to establish the equations of the sinking rolling wheel, to vertical load pressure relationship. Since vehicle movement on the Moon is a complex and on-going problem, the researcher is poised to simplify this problem of vertical loading of the wheel. In this paper, the quarter kinetic models of a manned lunar rover, which are both based on the rigid road and deformable lunar terrain, are used as the simulation models. With these kinetic models, the vibration simulations were conducted. The simulation results indicate that the quarter kinetic model based on the deformable lunar terrain accurately reflects the deformable terrain's influence on the vibration characteristics of a manned lunar rover. Additionally, with the quarter kinetic model of the deformable terrain, the vibration simulations of a manned lunar rover were conducted, which include a parametric analysis of the wheel parameters, vehicle speed, and suspension parameters. The results show that a manned lunar rover requires a lower damping value and stiffness to achieve better vibration performance.
\end{abstract}

\section{Introduction}

As a part of the deep space detection project of China, astronauts will land on the Moon from 2020 to 2030 to establish the lunar observation station and to detect available mineral resources, which will be used to build the basic facilities for further lunar exploration [1]. For the manned lunar-landing project, the vehicle plays a key role, in making it possible for the astronauts to complete long distance exploration tasks with heavy equipment and to transport samples back. Until now, the manned lunar rover vehicles belonging to the Project Apollo have been the main manned vehicle that has landed on the Moon and completed serious exploration $[2,3]$. However, with the limitations of research conditions, the studies of the American manned lunar rover are not perfect.

Given the enormous value of a manned lunar rover for landing and exploration, the development of new manned lunar rovers is rapidly occurring around the world. Until now, a number of manned lunar rovers with different concepts have been designed and manufactured globally. Among the performance considerations of the manned lunar rovers, both the vibration performance and the ride comfort are essential.

At present, some researchers have studied the vibration of the lunar rover. Gao et al. established a vibration model with seven degrees of freedom for a planetary-wheel lunar rover and optimized the choice of suspension spring stiffness and damping value [4]. At the same time, the authors proposed a revised method for equivalent surface roughness functions. In addition, this work established a kinetic model with 11 degrees of freedom for a six-wheeled, rocker-style lunar rover to analyze the ride comfort. X.-L. Wang and R.-B. Wang built a rigid-elastic coupling model for the lunar rover and determined the resonance frequency area by simulating the surface roughness of the lunar terrain [5].

Considering the characteristics of a manned lunar rover and the contact model of the wheel and terrain, this paper 


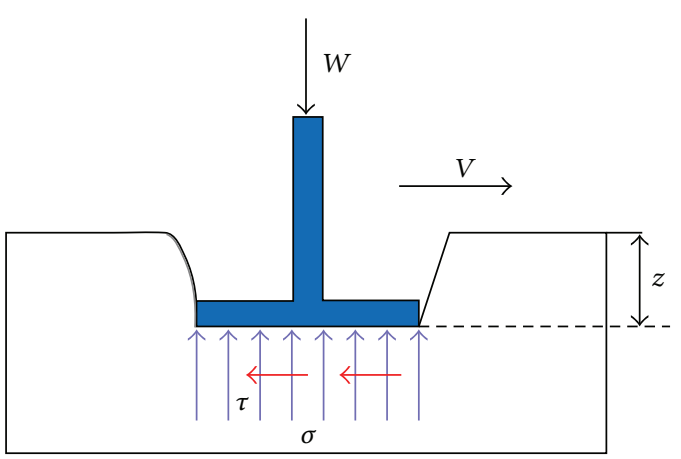

FIGURE 1: Bekker's contact model.

establishes a quarter kinetic model and analyzes the influence of wheel size on the vibration performance.

In this paper, the contact model of a rigid wheel and lunar terrain is established based on Bekker's equations $[6,7]$. Moreover, the quarter kinetic model of a manned lunar rover is established, which is used to study the influence of wheel parameters, suspension parameters, and vehicle speed on the vibration performance.

\section{Lunar Terrain Model}

Lunar terrain is similar to the sandy environment of the Earth with the addition of a variety of different-size meteorites distributed on the lunar surface $[8,9]$. Therefore, the lunar terrain will cause vibrations of a manned lunar rover when it is moving on the lunar surface. Additionally, wheels on the lunar terrain will sink because of the plastic deformation and elastic deformation of the terrain under the normal pressure of the wheel. The contact model between the wheel and the lunar terrain is a very complex, nonlinear contact model.

For the analysis of the contact model between the wheel and lunar terrain, three effective methods include the semiempirical method, finite element method, and analytical method [10-12]. Given the characters of a manned lunar rover, the semiempirical method is applied. Figure 1 shows the relationship of the normal stress and the wheel sinkage in Bekker's model; the following describes the contact model $[7,11]$ :

$$
\sigma=\left(\frac{k_{c}}{b}+k_{\varphi}\right) \cdot z^{n} .
$$

The variables are defined as follows: $\sigma(\mathrm{Pa})$ is the mean normal stress under the plate, $b(\mathrm{~m})$ is the short-edge length or the radius of plate, $n$ (dimensionless) is the sinkage exponent of the terrain, $z(\mathrm{~m})$ is the wheel sinkage, $k_{c}$ $\left(\mathrm{Pa} / \mathrm{m}^{n-1}\right)$ is the cohesive modulus of the terrain in Bekker's model, and $k_{\varphi}\left(\mathrm{Pa} / \mathrm{m}^{n}\right)$ is the frictional modulus of the terrain in Bekker's model. For the study in this paper, the $k_{c}=$ $1.4 \mathrm{~Pa} / \mathrm{m}^{n-1}$ and the $k_{\varphi}=820 \mathrm{kPa} / \mathrm{m}^{n-1}[13]$.

When driving a manned lunar rover, the wheel driving force is mainly provided by the shear stress between the wheel and the lunar terrain. The shear performance of the lunar terrain is shown with the shear force versus shear

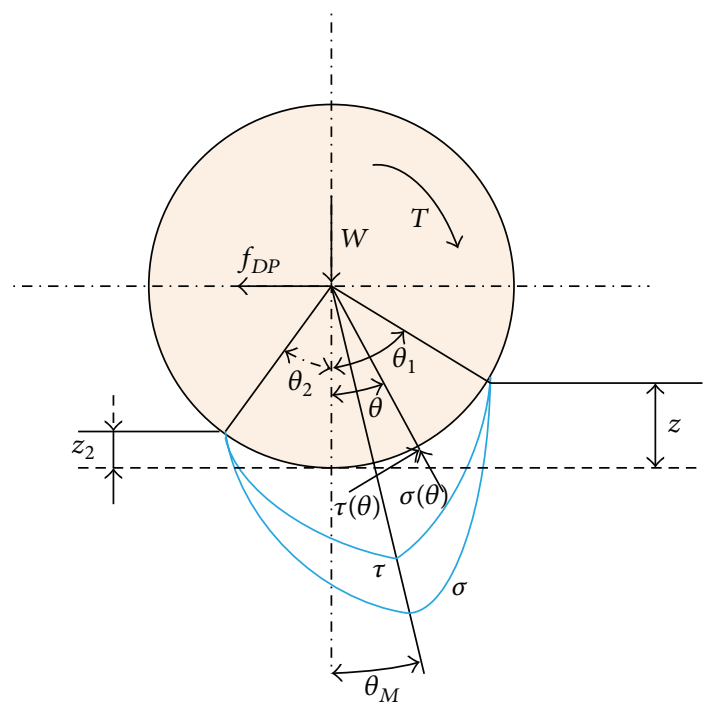

FIGURE 2: Wheel-soil interaction mechanics model.

displacement diagram. Based on Janosi's terrain shearing model [14], the relationship of the terrain shear stress and shear displacement is described by

$$
\tau=\tau_{\max }\left(1-e^{-j / j_{0}}\right)=(c+\sigma \tan \varphi)\left(1-e^{-j / j_{0}}\right) .
$$

The variables are defined as follows: $c(\mathrm{~Pa})$ is the cohesion of the terrain, $\varphi\left(^{\circ}\right)$ is the internal friction angle of the terrain, $j(\mathrm{~m})$ is the shear displacement of the terrain, and $j_{0}$ is the shear deformation modulus of the terrain. For the lunar terrain, the value of $c$ is in the range of $0.1 \mathrm{kPa}$ to $2.5 \mathrm{kPa}$, and $\varphi$ is in the range of 25 to 50 degrees [13].

\section{Wheel-Terrain Interaction Mechanics Model}

For a moving manned lunar rover, the wheels mainly bear the vertical force and longitudinal force. Figure 2 shows the stress distribution of a spinning wheel. The variables are defined as follows: $T(\mathrm{~N} \cdot \mathrm{m})$ is the driven torque of the wheel, $f_{\mathrm{DP}}(\mathrm{N})$ is the horizontal resistance force, $W(\mathrm{~N})$ is the vertical load, $\theta_{1}$ $\left({ }^{\circ}\right)$ is the entrance angle of the wheel moving on the terrain, $\theta_{2}\left({ }^{\circ}\right)$ is the leaving angle of the wheel moving on the terrain, and $\theta_{M}\left({ }^{\circ}\right)$ is the angular position of the maximum stress of the terrain acting on wheel.

As shown in Figure 2, the force balance consists of a stress system including the shearing force, the normal force, driven torque, the horizontal resistance, and the vertical load force. The normal stress and the shear stress change with both the entrance angle and leaving angle of the wheel moving on the terrain.

Lunar terrain is a type of elastic-plastic soil. Therefore, the wheel sinkage happens under the effect of lunar gravity and vertical vibration. The wheel sinkage is determined by the geometric parameters in Figure 2, and the relationship is shown in (3). In addition, the shear deformation, which is 
caused by the slipping between the wheel and the terrain, is described by [15]

$$
\begin{gathered}
z=r\left(1-\cos \theta_{1}\right), \\
j=r\left(\left(\theta_{1}-\theta\right)-(1-s)\left(\sin \theta_{1}-\sin \theta\right)\right) .
\end{gathered}
$$

The variables are defined as follows: $z(\mathrm{~m})$ is the depth of the wheel sinkage, and also is the distance from the low of wheel to the ground. $r(\mathrm{~m})$ is the wheel radius, and $s$ (dimensionless) is the slip ratio of the wheel.

When the wheel is in the static state, the normal stress under the wheel is symmetrically distributed, and the maximum stress occurs at the bottom-dead-center. If the wheel is in the rolling state, the maximum stress is in the front part of the wheel, which is caused by the wheel slipping. The following shows that the location of the maximum shear stress and normal stress on the wheel are coefficients of the wheel-soil interaction angel (dimensionless):

$$
\theta_{M}=\left(c_{1}+c_{2}|s|\right) \theta_{1} .
$$

The normal and shear stress distribution equations of the Wong-Reece model are shown by (6) and (7), respectively [15, 16]. Consider the following:

$$
\begin{gathered}
\sigma_{1}(\theta)=\left(\frac{k_{c}}{b}+k_{\varphi}\right) r^{n}\left(\cos \theta-\cos \theta_{1}\right)^{n}, \quad\left(\theta_{M} \leq \theta \leq \theta_{1}\right), \\
\sigma_{2}(\theta)=\left(\frac{k_{c}}{b}+k_{\varphi}\right) r^{n}[ \\
-\cos \left(\theta_{1}-\frac{\theta-\theta_{2}}{\theta_{M}-\theta_{2}} \times\left(\theta_{1}-\theta_{M}\right)\right) \\
\left.-\cos \theta_{1}\right]^{n}, \quad\left(\theta_{2} \leq \theta<\theta_{M}\right),
\end{gathered}
$$

$$
\begin{array}{r}
\tau_{1}(\theta)=\left[c+\sigma_{1}(\theta) \tan \varphi\right]\left(1-\exp \left(-\frac{j}{j_{0}}\right)\right), \\
\left(\theta_{M} \leq \theta \leq \theta_{1}\right), \\
\tau_{2}(\theta)=\left[c+\sigma_{2}(\theta) \tan \varphi\right]\left(1-\exp \left(-\frac{j}{j_{0}}\right)\right), \\
\left(\theta_{2} \leq \theta \leq \theta_{M}\right) .
\end{array}
$$

As Figure 2 demonstrated, the vertical load on the wheel from the terrain consists of the vertical component of the normal stress and the vertical component of the shear stress. From this, the vertical load on the wheel can be obtained by (8). In this equation, $b(\mathrm{~m})$ is the width of the wheel:

$$
W=b r \int_{\theta_{2}}^{\theta_{1}}(\sigma(\theta) \cos (\theta)+\tau(\theta) \sin (\theta)) d \theta .
$$

In order to achieve sufficient driving forces, lugs are added to the rigid wheel to provide a larger shear force for the manned lunar rover. The contact model of the lunar terrain and rigid wheel with lugs is complicated; therefore, this paper does not consider the lugs. This paper mainly studies the smooth rigid wheel and the vertical load. According to our previous research $[16,17]$, the shear stress of the smooth rigid wheel has almost no influence on the vertical load, and, thus, it can be ignored. Simplifying the equation for the vertical load, we can write

$$
\begin{aligned}
W & \approx b r \int_{\theta_{2}}^{\theta_{1}} \sigma(\theta) \cos (\theta) d \theta \\
& =b r\left(\int_{\theta_{2}}^{\theta_{M}} \sigma_{1}(\theta) \cos (\theta) d \theta+\int_{\theta_{M}}^{\theta_{1}} \sigma_{2}(\theta) \cos (\theta) d \theta\right) .
\end{aligned}
$$

Equation (9) is a complex, nonlinear equation. Janosi et al. describe a method that has simplified (9) [14]. In this work, they describe $\sigma_{M}=k_{s} r^{n}\left(\cos \theta_{M}-\cos \theta_{1}\right)^{n}$, where the variable $k_{s}$ (dimensionless) is the equivalent sinkage modulus of the terrain, defined as $k_{s}=k_{c} / b+k_{\varphi}$. Equation (10) shows the simplified result of (6) [17]. Consider the following:

$$
\begin{aligned}
& \sigma_{1}(\theta) \approx \sigma_{1}^{L}(\theta)=\frac{\sigma_{M}\left(\theta_{1}-\theta\right)}{\left(\theta_{1}-\theta_{M}\right)} \quad\left(\theta_{M} \leq \theta \leq \theta_{1}\right), \\
& \sigma_{2}(\theta) \approx \sigma_{2}^{L}(\theta)=\frac{\sigma_{M}\left(\theta-\theta_{2}\right)}{\left(\theta_{M}-\theta_{2}\right)} \quad\left(\theta_{2} \leq \theta<\theta_{M}\right) .
\end{aligned}
$$

By substituting (10) into (9), we obtain

$$
W=\frac{2 b r \sigma_{M}\left(1-\cos \theta_{1}\right)}{\theta_{1}}=\frac{2 b z \sigma_{M}}{\theta_{1}}=\frac{2 b k_{s} z^{n+1}}{\theta_{1}} \text {. }
$$

The entrance angle of a manned lunar rover wheel is small and changes with a change in the depth of the wheel sinkage and the slip angle. The wheel entrance angle is describes by

$$
\theta_{1}=\sqrt{\frac{2 z}{r}} .
$$

Substituting (12) into (1) produces [17]

$$
W=\frac{2 b k_{s} z^{n+1}}{\theta_{1}} \approx \sqrt{2 r} b k_{s} z^{n+1 / 2} .
$$

\section{Kinetic Model of a Manned Lunar Rover}

The quarter kinetic model is an efficient method to study the vibration performance of a moving manned lunar rover. The assumptions of the quarter kinetic model are that the wheel is a single rigid body, only vertical vibration occurs, and the wheel must be in contact with the terrain.

4.1. Kinetic Model of a Manned Lunar Rover on a Rigid Road. In the studies of traditional vehicles, the deformation of the road surface is not taken into consideration in dynamic performance, and the contact point is considered as a type of effective simplified model for the contact area of the wheel and road. First, the quarter kinetic model of a manned lunar rover on a nondeformable road was built as shown in Figure 3 . The kinetic equations are described by

$$
\begin{aligned}
& m_{1} \ddot{z}_{1}+c\left(\dot{z}_{1}-\dot{z}_{2}\right)+k\left(z_{1}-z_{2}\right)=0, \\
& m_{2} \ddot{z}_{2}+c\left(\dot{z}_{2}-\dot{z}_{1}\right)+k\left(z_{2}-z_{1}\right)=0 .
\end{aligned}
$$




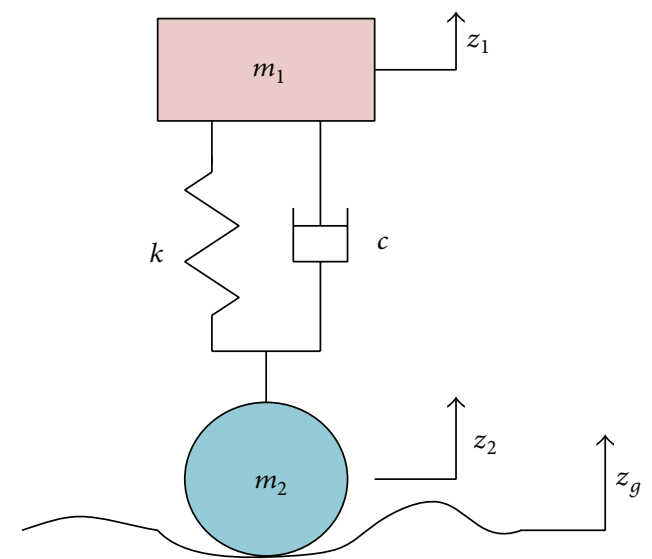

Figure 3: The quarter kinetic model of a manned lunar rover on a rigid road.

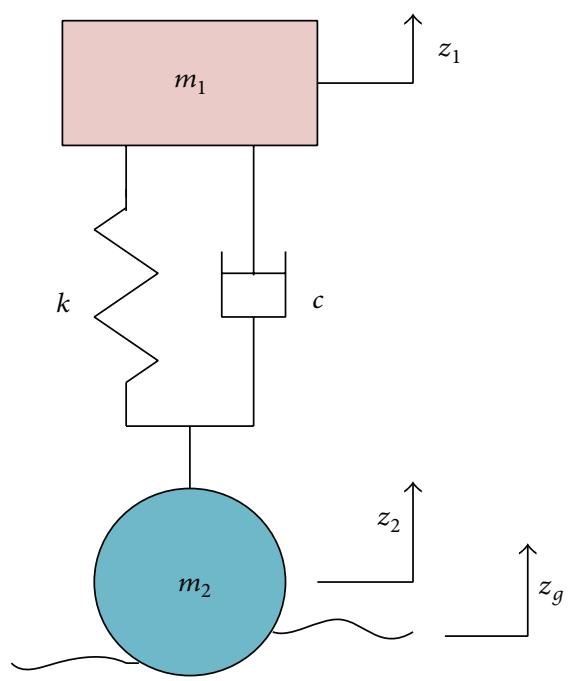

FIgURE 4: The quarter kinetic model of a manned lunar rover on a deformable terrain.

The variables are defined as follows: $m_{1}(\mathrm{~kg})$ is the sprung mass, $m_{2}(\mathrm{~kg})$ is the unsprung mass, $k(\mathrm{kN} / \mathrm{m})$ is the suspension stiffness, $c(\mathrm{kN} /(\mathrm{m} / \mathrm{s}))$ is the damping coefficient of the suspension, $z_{1}(\mathrm{~m})$ is the deformation of the sprung mass, $z_{2}(\mathrm{~m})$ is the deformation of the unsprung mass, and $z_{g}$ $(\mathrm{m})$ is the deformation of the ground.

4.2. Kinetic Model of a Manned Lunar Rover on a Deformable Terrain. The lunar terrain will sink when in contact with the rigid wheel, which will press the wheel surface as seen in Figure 2. Figure 4 depicts the kinetic model of a manned lunar rover on a deformable terrain. The definition of the variables is the same as those in Figure 3. The kinetic equations are described by

$$
\begin{gathered}
m_{1} \ddot{z}_{1}+c\left(\dot{z}_{1}-\dot{z}_{2}\right)+k\left(z_{1}-z_{2}\right)=0, \\
m_{2} \ddot{z}_{2}+c\left(\dot{z}_{2}-\dot{z}_{1}\right)+k\left(z_{2}-z_{1}\right)=\Delta F_{n} .
\end{gathered}
$$

In (15), $\Delta F_{n}(\mathrm{~N})$ is the vertical load on the wheel, which comes from the terrain, and is equal to $W(\mathrm{~N})$. Combining this equation with (13) results in

$$
\Delta F_{n}=W=\sqrt{2 r} b k_{s} z^{n+1 / 2} .
$$

For (16), the sinkage exponent of the terrain relates to the slip ratio. According the study of Ding et al. [16, 17], the sinkage exponent of the terrain can be treated as linear. In this case, the sinkage exponent is constant at $n=1$. Then, the vertical deformation of the rigid wheel mainly relates to the roughness of the lunar terrain.

\section{Surface Unevenness Simulation of the Lunar Terrain}

Since there are few studies on the surface roughness of the lunar terrain, the recent topography and geomorphology are mainly at the kilometer level. Obviously, the size of the manned lunar rover has warranted the need for surface unevenness data at the meter level. The surface roughness model was built based on the expressive method of road roughness for traditional vehicles. The power spectral density (PSD) expression of the lunar terrain surface unevenness is defined by [18]

$$
G_{d}(n)=G_{d}\left(n_{0}\right) \cdot\left(\frac{n}{n_{0}}\right)^{-w}, \quad(n>0) .
$$

The variables are defined as follows: $n_{0}$ is the reference frequency, $G_{d}\left(n_{0}\right)$ is the coefficient of the road roughness, $G_{d}(n)$ is the road roughness, and $w$ is the frequency exponent that is experientially determined to be 2 .

The method used to filter white noise is a type of road roughness reconstruction method, which has a high simulation precision [18]. The road roughness equation constructed by this model is descried by.

$$
\dot{q}(t)=2 \pi f_{0} q(t)=2 \pi n_{0} \sqrt{G q\left(n_{0}\right) v} w(t) .
$$

The variables are defined as follows: $f_{0}$ is the lower cut-off frequency of the filter, $q(t)$ is the surface roughness amplitude of a random road, and $w(t)$ is the uniformly distributed unit of white noise with an average value of 0 and intensity of 1 .

\section{Simulation and Analysis}

Table 1 displays the vehicle parameters before the simulation. In the Chinese lunar exploration project [19], the manned lunar rover should transport two astronauts, and the combined weight is $660 \mathrm{~kg}$. Obviously, the wheel size has a vast influence on the mechanical properties. Referencing the size of the current lunar rover wheels, the width ranges from $100 \mathrm{~mm}$ to $300 \mathrm{~mm}$, and the radius ranges from $200 \mathrm{~mm}$ to $500 \mathrm{~mm}$. Therefore, the wheel width was chosen to be $230 \mathrm{~mm}$, and the radius was chosen to be $410 \mathrm{~mm}$. The velocity of the lunar rover ranges from $5 \mathrm{~km} / \mathrm{h}$ to $18 \mathrm{~km} / \mathrm{h}$. In this study, the velocity used was $10 \mathrm{~km} / \mathrm{h}$. Table 1 contains 
TABLE 1: Parameters of the manned lunar rover used for the simulations.

\begin{tabular}{lcc}
\hline Number & Parameter & Value \\
\hline 1 & Wheel radius & $410 \mathrm{~mm}$ \\
2 & Wheel width & $230 \mathrm{~mm}$ \\
3 & Sprung mass & $150 \mathrm{~kg}$ \\
4 & Unsprung mass & $15 \mathrm{~kg}$ \\
5 & Suspension stiffness & $6260 \mathrm{~N} / \mathrm{m}$ \\
6 & Suspension damper & $5753 \mathrm{~N} \cdot \mathrm{s} / \mathrm{m}$ \\
\hline
\end{tabular}

the parameters of the manned lunar rover used in our simulations.

In order to investigate the vibration performance of a manned lunar rover on both rigid road and deformable terrain, the kinetic models were simulated using (14) and (15), respectively. The PSD of the rigid road and deformable terrain was based on the road roughness of level E road for a traditional vehicle, which is shown in Figure 5. Figure 6 shows that the vertical vibration acceleration of the lunar rover on the rigid road is much greater than that on the deformable terrain. When the lunar rover moves on the rigid road, the surface roughness transferred to the wheel directly, creating a vigorous vibration. However, once the lunar rover moved on the deformable terrain, the terrain sinkage absorbs the energy of the vibration, as it plays the role of a damper. On the Moon, most of the area is elastic-plastic terrain with few areas covered by meteorites of varying size. Therefore, the kinetic model of the lunar rover on the deformable terrain is more suitable to study the vibration performance of the manned lunar rover.

Through the wheel, the manned lunar rover and the lunar terrain interact. The parameters of the wheel affect not only the drive performance, but also the vibration performance of the manned lunar rover. Figure 6 shows the acceleration and displacement of the sprung mass of the lunar rover with different wheel radii. The acceleration and displacement of the sprung mass decreased with a decrease in road deformation. The vibration acceleration was at a minimum when the wheel radius was $0.15 \mathrm{~m}$ and increased with increasing wheel radius.

Figure 7 shows the acceleration of the manned lunar rover with different wheel widths. The wheel width had a considerable influence on the acceleration of the sprung mass. When the vibration acceleration was low, the wider wheel weakened the vibration; however, when the acceleration was high, the wider wheel enhanced the vibration.

Figure 8 shows the acceleration and displacement of the manned lunar rover sprung mass with different vehicle velocities. We observe that the vehicle velocity has little influence on the acceleration but shows obvious effects on the displacement. With an increase of vehicle velocity, the displacement of the sprung mass decreased gradually, which was a result of minor changes in the acceleration of the sprung mass under different vehicle velocities. Higher vehicle velocities correlated with decreased response times of the sprung mass, which led to a reduction of the displacement of the sprung mass.

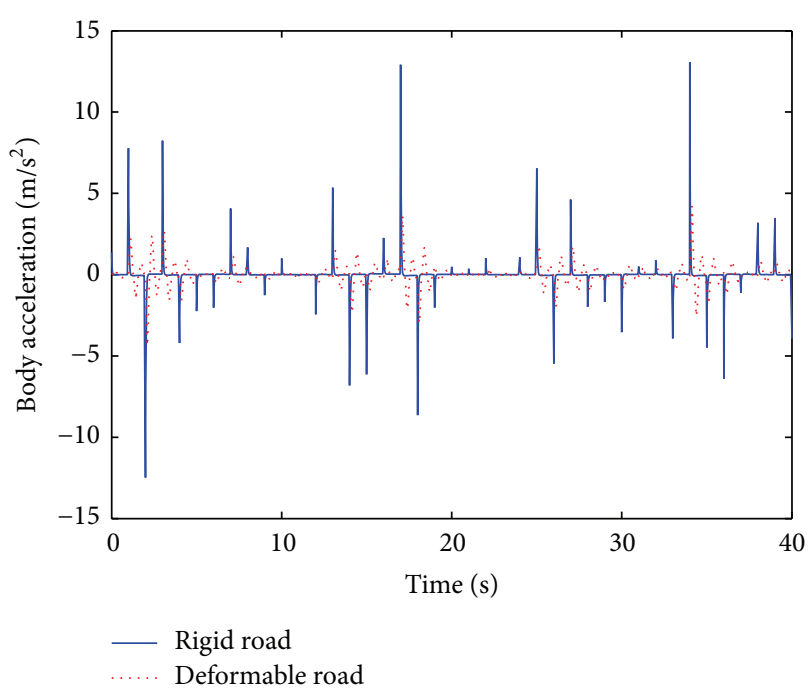

FIGURE 5: Comparison between the kinetic models of the rigid road and deformable terrain.

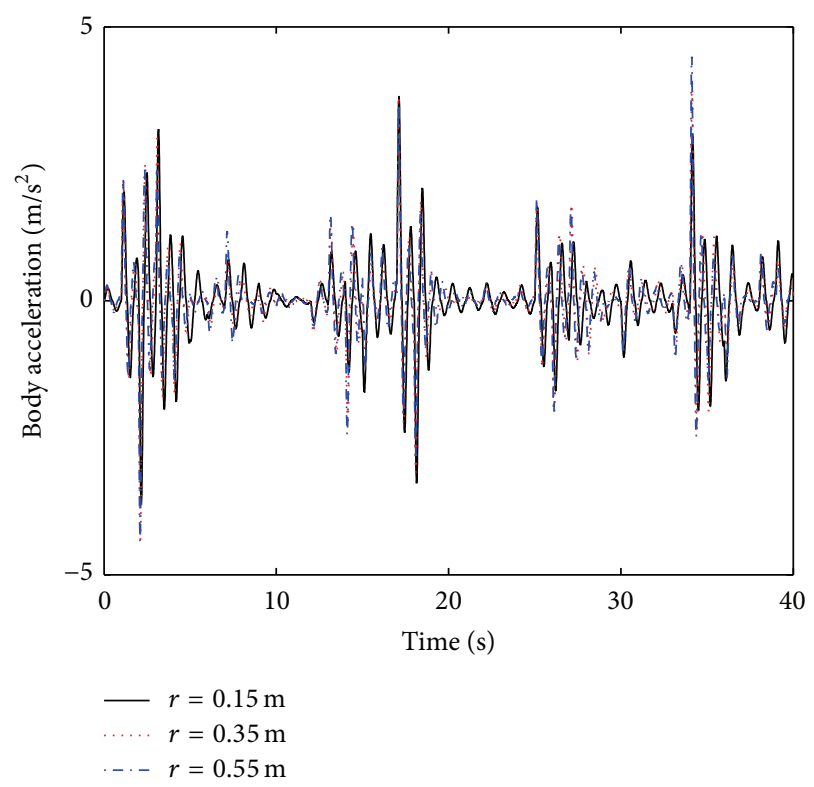

FIgURE 6: Acceleration of the sprung mass of different wheel radii.

The acceleration and displacement of the sprung mass of the manned lunar rover with different stiffnesses are displayed in Figure 9. The vibration variables indicated minor changes when the suspension stiffness changed from $3000 \mathrm{~N} / \mathrm{m}$ to $9000 \mathrm{~N} / \mathrm{m}$. However, when the suspension stiffness changed from $6000 \mathrm{~N} / \mathrm{m}$ to $60000 \mathrm{~N} / \mathrm{m}$, obvious changes in vibration were observed. At a high stiffness, the sprung mass vibrated violently, indicating reduced ride comfort.

The damping coefficient also had a considerable effect on the vibration performance, as shown in Figure 10. The acceleration is damped quickly at high suspension damping coefficients because a damper with a high damping coefficient more quickly absorbs the energy of vibrations. However, once the road simulation amplitude increased, the acceleration 


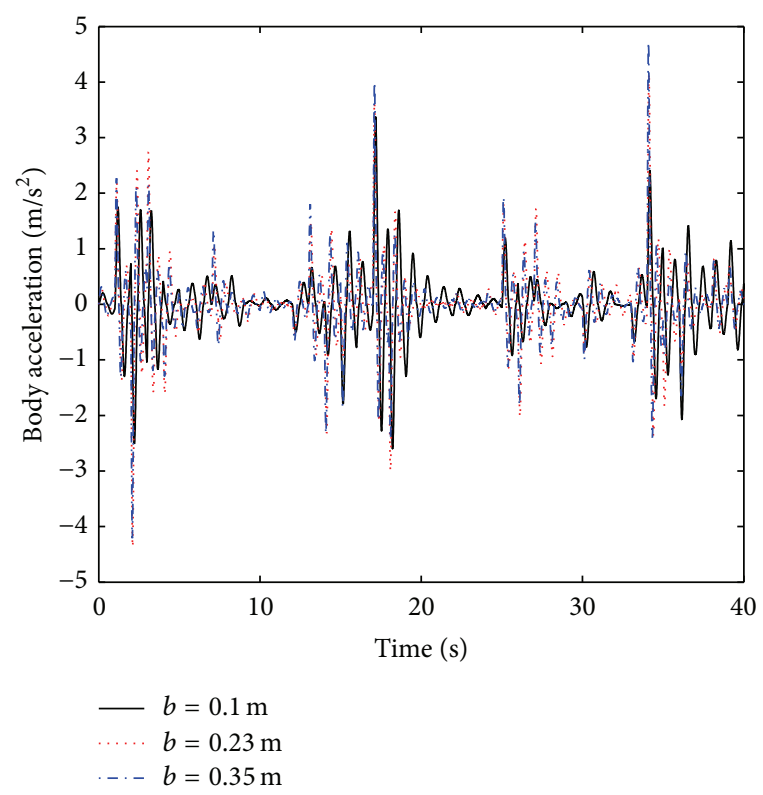

(a)

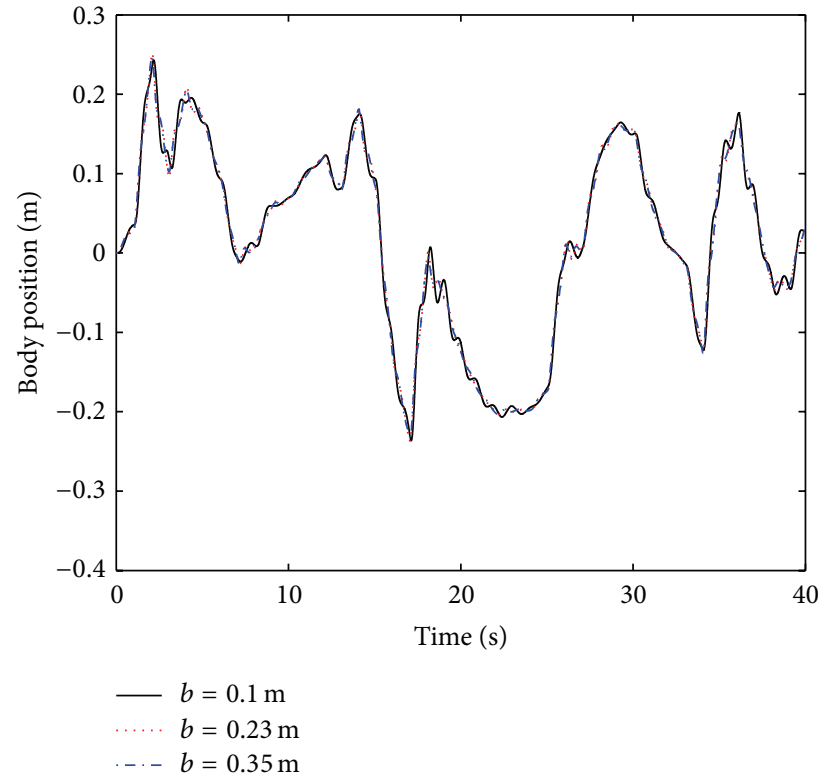

(b)

Figure 7: Acceleration and displacement of the sprung mass with different wheel widths.

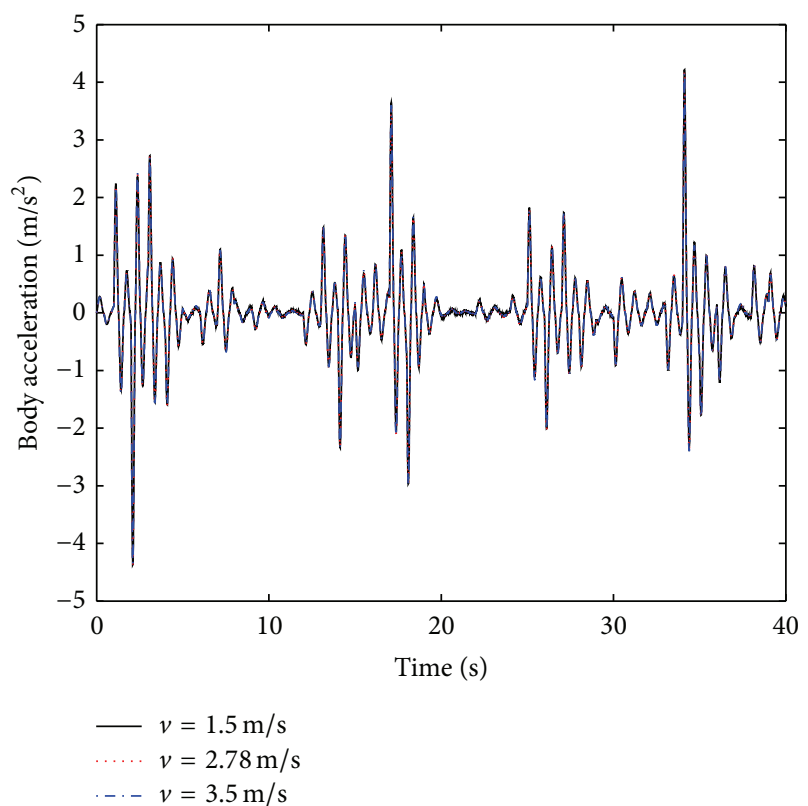

(a)

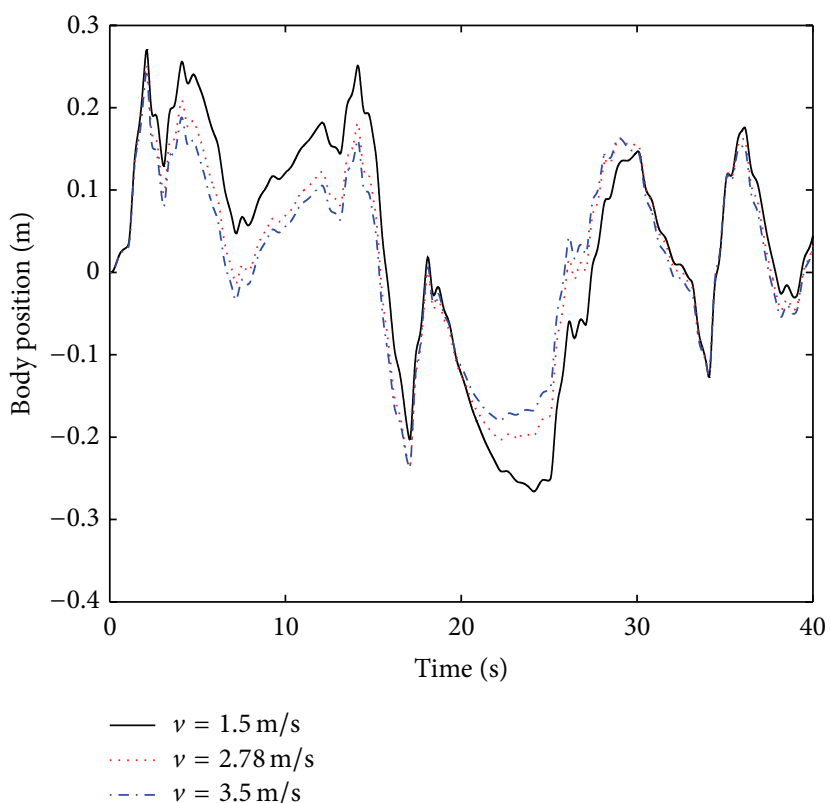

(b)

FIGURE 8: Acceleration and displacement of the sprung mass with different vehicle velocities.

increased as well. Therefore, too high of a damping coefficient is not beneficial to the ride comfort of a manned lunar rover.

\section{Conclusions}

(1) The quarter kinetic model of a manned lunar rover can adequately simulate the vibration performance of the vehicle. When the manned lunar rover was on the deformable terrain, the vibration performance was greatly affected by the stress between the wheel and terrain. Note that the quarter kinetic model can be used only under the condition that the wheels maintain contact with the terrain. Further investigation is needed for the vibration performance when the wheel loses contact with the terrain.

(2) The wheel size of the manned lunar rover affected the vibration of the sprung mass. A bigger wheel 


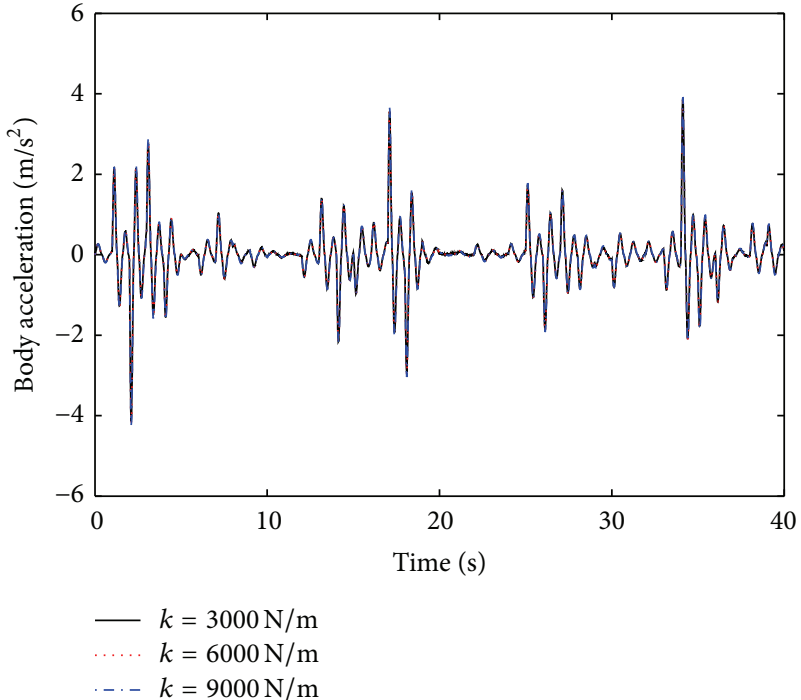

(a)

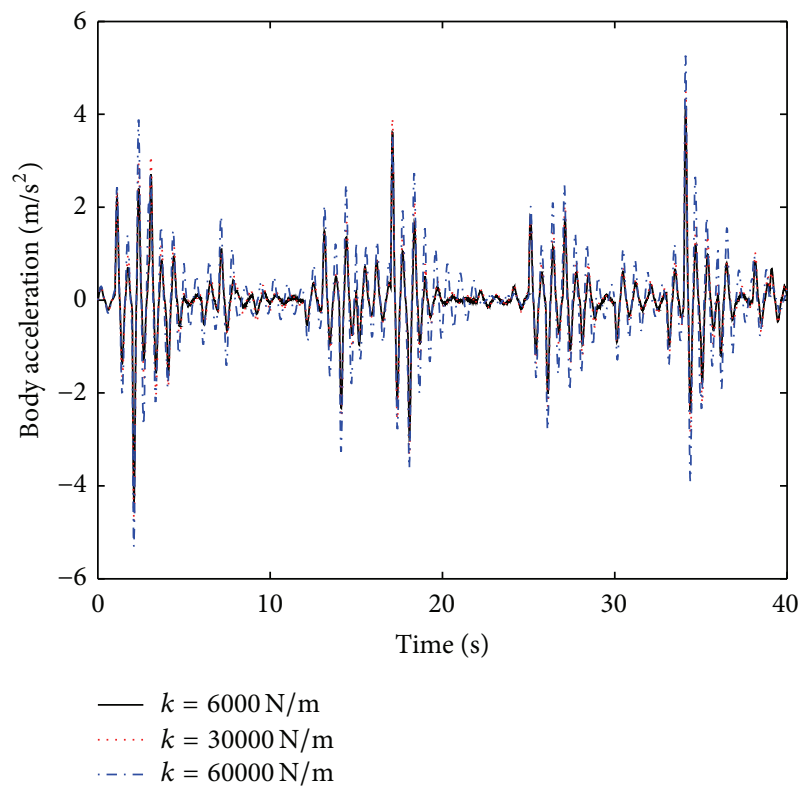

(c)

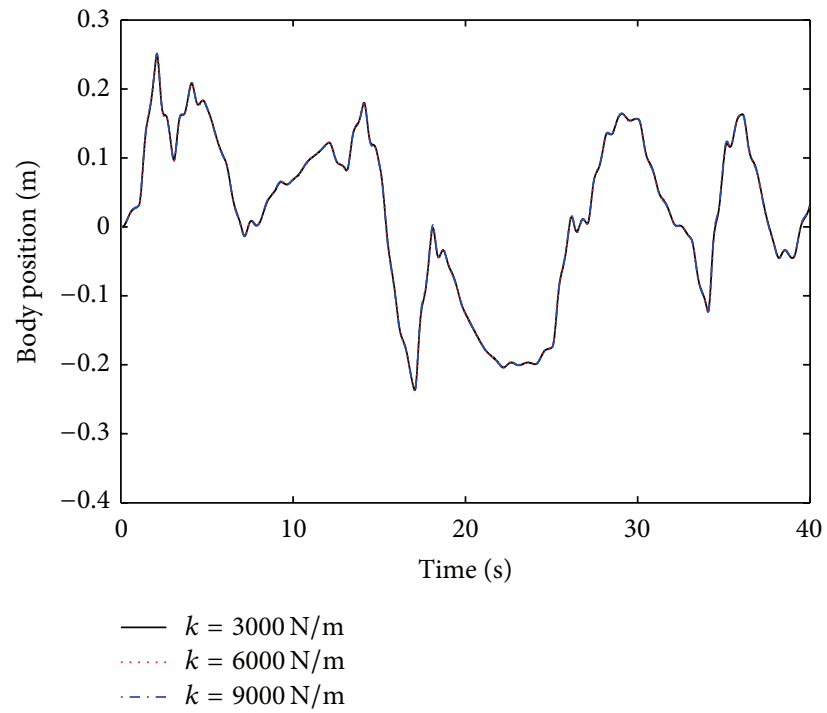

(b)

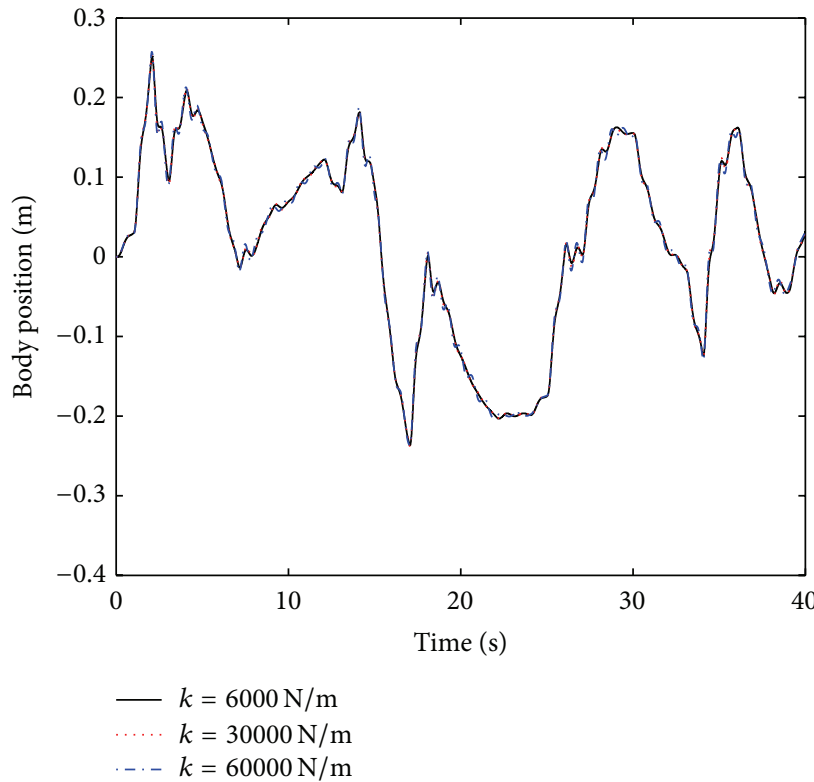

(d)

FIGURE 9: Acceleration and displacement of the sprung mass with different suspension stiffnesses.

radius correlated with better obstacle-climbing performance, but also a higher acceleration of the sprung mass. In addition, the influence of the wheel width on the vibration performance was found to be complicated, though mainly determined by the surface roughness of the lunar terrain. On a gentle road, a wider wheel decreased the vibration acceleration. While on a bumpy road, a wider wheel increased the vibration acceleration.

(3) The vehicle velocity had little influence on the vibration acceleration but obvious effects on the vibration displacement of the sprung mass of a manned lunar rover. With an increase in vehicle velocity, the displacement of the sprung mass decreased. This is because a high velocity shortens the action time of the acceleration, which changes minimally with different velocities, causing a decrease in the displacement of the sprung mass.

(4) The suspension conditions included the stiffness and damping value. Lower stiffness indicated lower vibration. Obviously, the vibration parameters were equal when the stiffness ranged over a small scale. As opposed to the suspension stiffness, the variation in the suspension damping value can greatly affect the vibration performance. At a high damping value, the suspension was able to absorb the vibration energy on a massive scale but could not effectively decrease the vibration acceleration amplitude. On the contrary, 


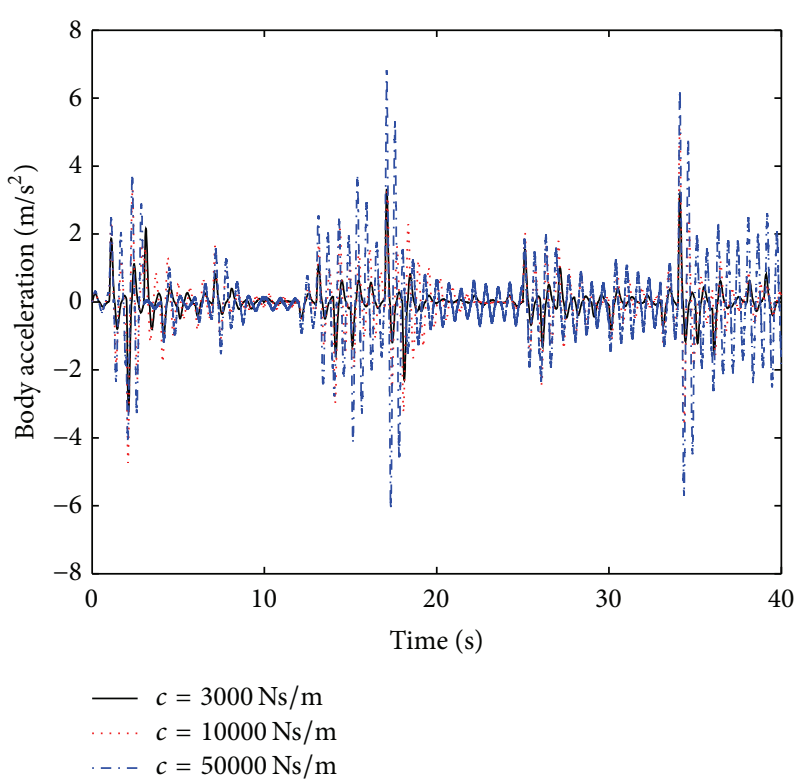

(a)

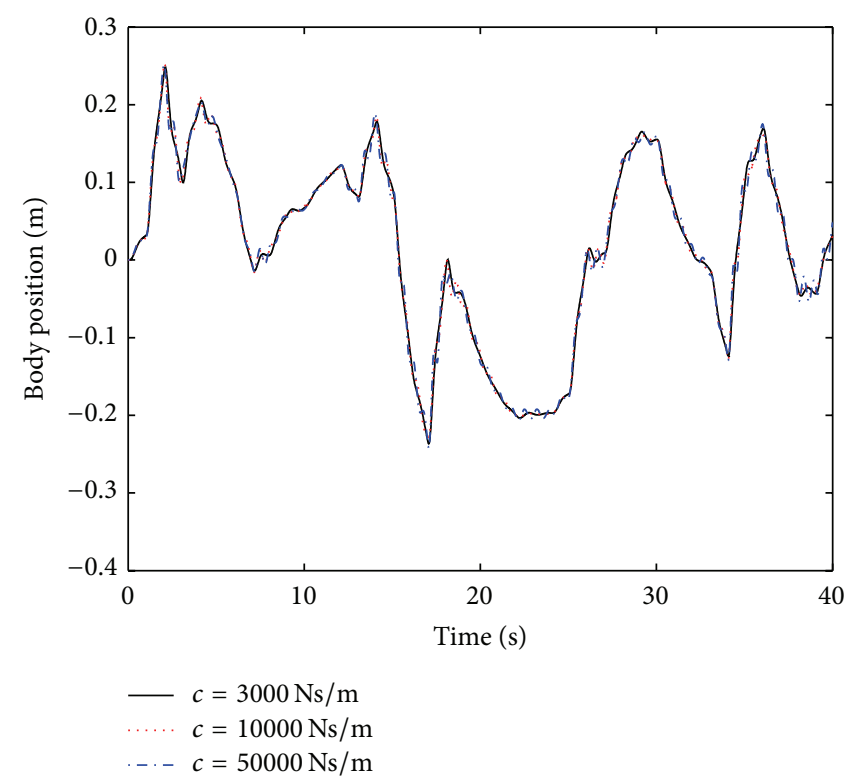

(b)

FIGURE 10: Acceleration and displacement of the sprung mass with different suspension damping values.

at a low damping value, the suspension could not absorb the vibration energy effectively. Generally, the choice of the damping value should consider various performance conditions of the manned lunar rover.

(5) In this paper, the shear force between the wheel and terrain was ignored. The vertical component of the shear force had a considerable effect on the vertical load when the lunar rover required a large driving force, which greatly affected the vibration performance.

\section{Conflict of Interests}

The authors declare that there is no conflict of interests regarding the publication of this paper.

\section{Acknowledgments}

This study was supported in part by the National Natural Science Foundation of China (Grant no. 61370033/51275106), National Basic Research Program of China (Grant no. 2013CB035502), the Fundamental Research Funds for the Central Universities (Grant no. HIT.BRETIII.201411), S\&T Innovation Project of CASC-HIT S\&T Innovation Center (Grant no. CASC-HIT11-1A03), Foundation of Chinese State Key Laboratory of Robotics and Systems (Grant No. SKLRS2014-MS-09), and the "111 Project" (Grant no. B07018).

\section{References}

[1] L. Long, "On issues of China manned lunar exploration," Missiles and Space Vehicles, no. 6, pp. 1-5, 2010.
[2] R. D. Launius, "Project Apollo in American memory and myth," in Proceedings of the 7th International Conference and Exposition on Engineering, Construction, Operations and Business in Space, pp. 1-13, March 2000.

[3] M. R. Grabois, "Apollo: Learning from the past, for the future," Acta Astronautica, vol. 68, no. 7-8, pp. 1353-1360, 2011.

[4] H.-B. Gao, Q.-X. Meng, Z.-Q. Deng, H.-T. Fang, J.-G. Tao, and $\mathrm{M} . \mathrm{Hu}$, "Analysis of dynamic load between wheels of the planetary wheel lunar rover and ground," Journal of Harbin Institute of Technology, vol. 38, no. 4, pp. 523-527, 2006.

[5] X.-L. Wang and R.-B. Wang, "Analysis of lunar rover vibration characteristics based on rigid-flexible coupled model," Journal of Jilin University (Engineering and Technology Edition), vol. 42, no. 2, pp. 279-284, 2012.

[6] M. G. Bekker, Theory of Land Locomotion, University of Michigan Press, Ann Arbor, Mich, USA, 1956.

[7] M. G. Bekker, Introduction to Terrain-Vehicle Systems, University of Michigan Press, Ann Arbor, Ill, USA, 1969.

[8] Y. Zhao, H. S. Lv, L. Li, L. Guo, and M. Zhang, "Lunar terrain construction and application for Lunar Rover," Information Technology Journal, vol. 12, no. 23, pp. 7201-7207, 2013.

[9] Q. Su, Y. Zhao, K. Yang, and S. Zhang, "Lunar terrain and mineral's abundance automatic analysis," Optik, vol. 125, no. 3, pp. 1278-1282, 2014.

[10] S. Park, A. A. Popov, and D. J. Cole, "Influence of soil deformation on off-road heavy vehicle suspension vibration," Journal of Terramechanics, vol. 41, no. 1, pp. 41-68, 2004.

[11] G. Grant, L. Sean, and G. Richard, "Off-road vehicle locomotion using Bekker's model," in The International Society for Optical Engineering, vol. 4024 of Proceedings of SPIE, pp. 127-136, 2000.

[12] G. Michel and C. Edouard, "A new soil-vehicle interaction model for predicting off road mobility performances," in Proceedings of the 16th International Conference of the International Society for Terrain Vehicle Systems (ISTVS '08), pp. 108-113, Turin, Italy, November 2008. 
[13] L. Ding, H. Gao, Z. Deng, L. Xiong, J. Guo, and Y. Lu, "An approach of identifying mechanical parameters for lunar soil based on integrated wheel-soil interaction terramechanics model of rovers," Acta Aeronautica et Astronautica Sinica, vol. 32, no. 6, pp. 1112-1123, 2011.

[14] Z. J. Janosi, R. A. Liston, L. A. Martin et al., "Commercial offroad vehicles," in Proceedings of the Automotive Engineering Congress, SAE International, Detroit, Mich, USA, January 1970.

[15] J.-Y. Wong and A. R. Reece, "Prediction of rigid wheel performance based on the analysis of soil-wheel stresses part I. Performance of driven rigid wheels," Journal of Terramechanics, vol. 4, no. 1, pp. 81-98, 1967.

[16] L. Ding, H.-B. Gao, Z.-Q. Deng, J.-G. Tao, and L.-B. Xiong, "Wheel-soil interaction mechanics model for lunar rover: decoupling and application," Journal of Harbin Institute of Technology, vol. 43, no. 1, pp. 56-61, 2011.

[17] L. Ding, H. Gao, Y. Li, G. Liu, and Z. Deng, "Improved explicitform equations for estimating dynamic wheel sinkage and compaction resistance on deformable terrain," Mechanism and Machine Theory, vol. 86, pp. 235-264, 2015.

[18] Y. Wang, Ch. Li, and Z. Ma, "Simulation on vehicle ride comfort based on ADAMS/Cars ride," Machinery Design \& Manufacture, no. 4, pp. 81-82, 2010.

[19] Z.-Q. Deng, X.-B. Fan, H.-B. Gao, and L. Ding, "Review and key techniques for locomotive system of manned lunar rovers," Journal of Astronautics, vol. 33, no. 6, pp. 675-689, 2012. 

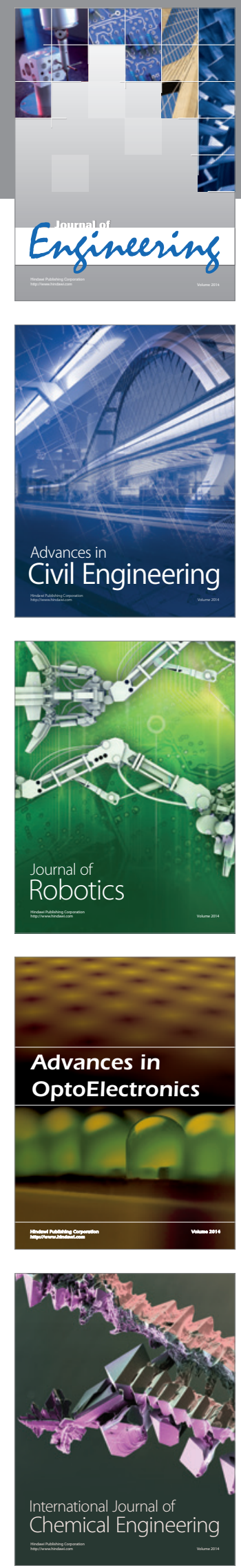

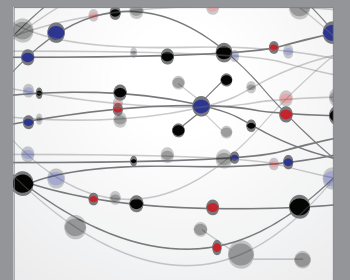

The Scientific World Journal
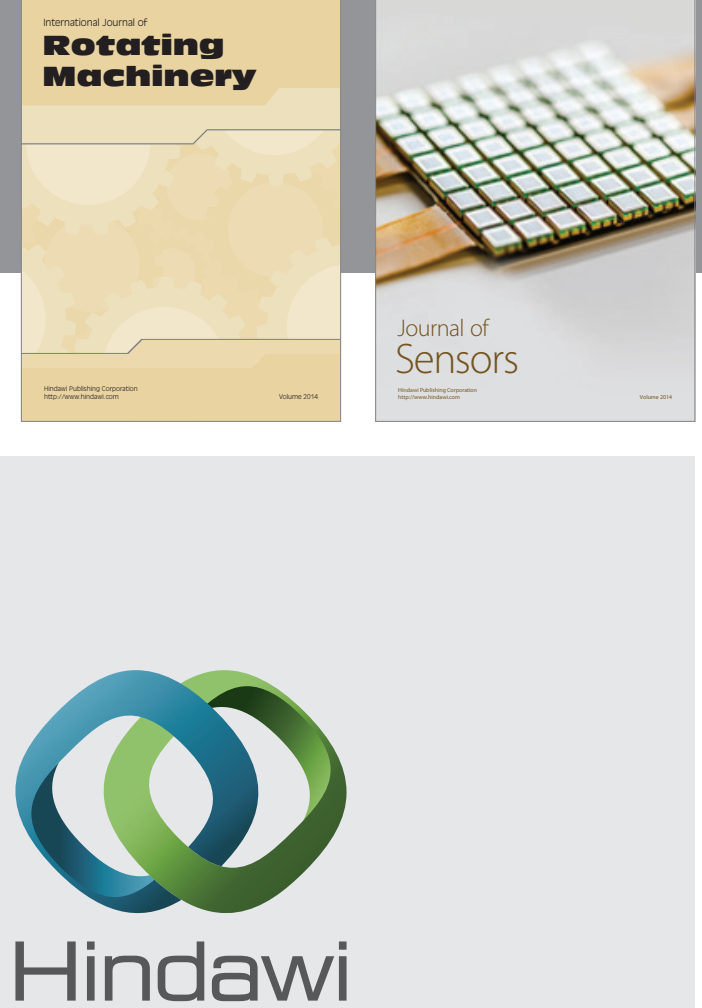

Submit your manuscripts at http://www.hindawi.com
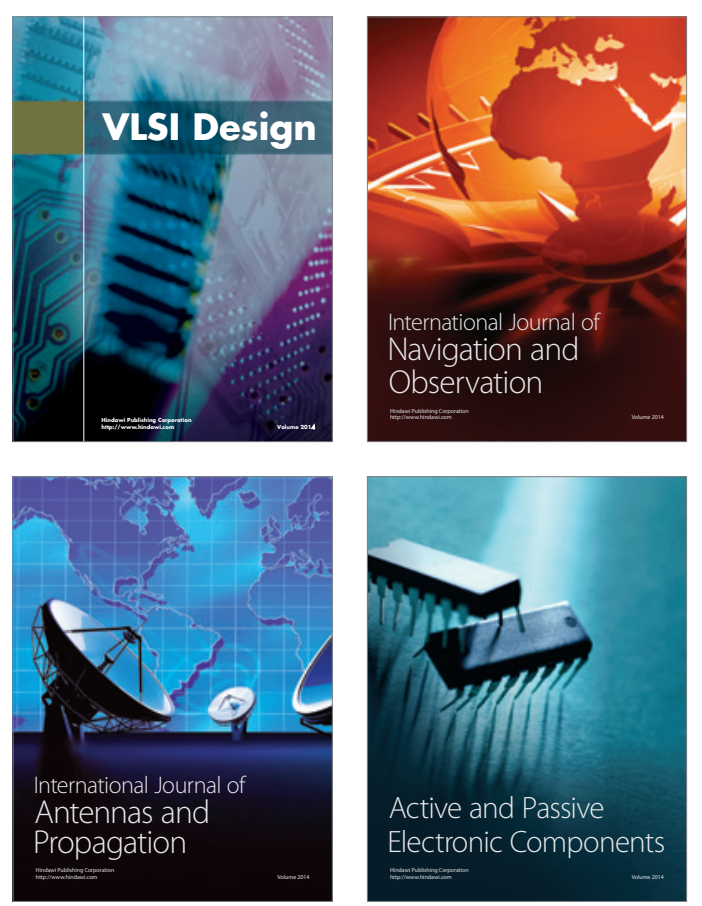
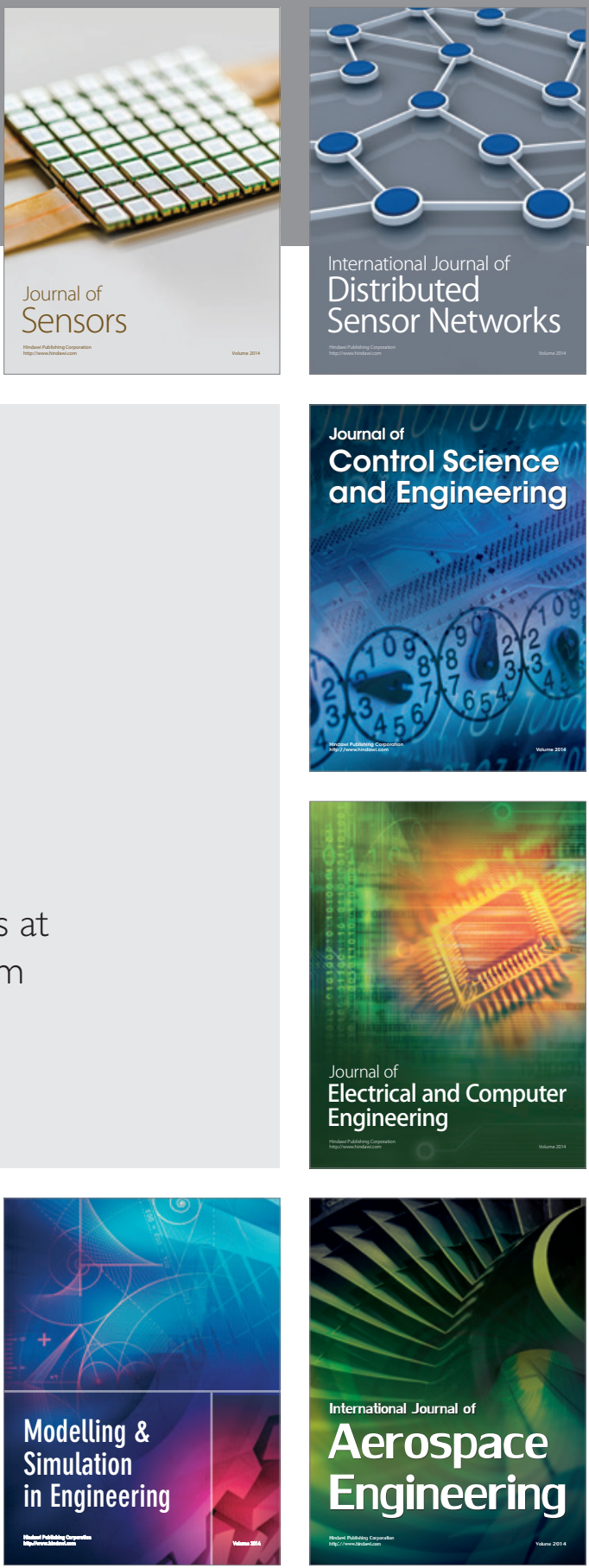

Journal of

Control Science

and Engineering
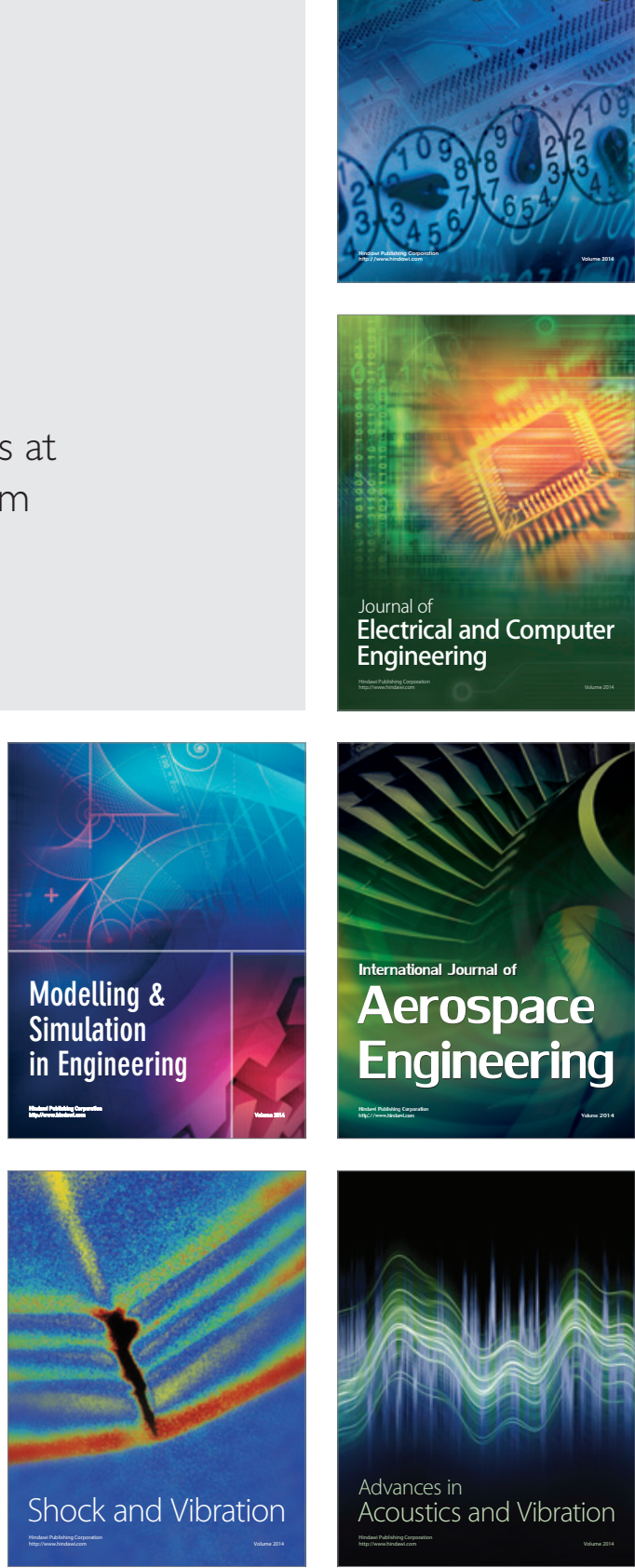